\title{
Review Article \\ Right Ventricular Dysfunction and Failure in Chronic Pressure Overload
}

\author{
Marc A. Simon ${ }^{1,2}$ and Michael R. Pinsky ${ }^{1,2}$ \\ ${ }^{1}$ Cardiovascular Institute, University of Pittsburgh, Scaife Hall S-554, 200 Lothrop Street, Pittsburgh, PA 15213, USA \\ ${ }^{2}$ Department of Critical Care Medicine, University of Pittsburgh, Scaife Hall S-554, 200 Lothrop Street, Pittsburgh, PA 15213, USA
}

Correspondence should be addressed to Marc A. Simon, simonma@upmc.edu

Received 7 December 2010; Accepted 25 January 2011

Academic Editor: Georgios Giannakoulas

Copyright (C) 2011 M. A. Simon and M. R. Pinsky. This is an open access article distributed under the Creative Commons Attribution License, which permits unrestricted use, distribution, and reproduction in any medium, provided the original work is properly cited.

Right ventricular (RV) dysfunction is the main cause of death in pulmonary arterial hypertension (PAH). Our understanding of the pathophysiology of RV dysfunction is limited but improving. Methods to better diagnose RV dysfunction earlier and treatments specifically designed to minimize or reverse the remodeling process are likely to improve outcomes. We review the current understanding of RV dysfunction in chronic pressure overload and introduce some novel insights based on recent investigations into pathophysiology, diagnosis, and treatment.

\section{Introduction}

Dysfunction of the right ventricle (RV) can occur in a number of clinical scenarios including pressure overload, cardiomyopathies, ischemic, congenital, or valvular heart disease, arrhythmias, and sepsis. Pressure overload can occur in an acute or chronic setting. Diagnosis is made on the compilation of data from the history and physical examination, electrocardiogram, chest X-ray, echocardiogram, and invasive hemodynamics. RV failure is associated almost universally with poor prognosis. Early recognition is essential to improve outcomes. Although pressure overload can occur with pulmonary valvular stenosis, the most common cause of pressure overload is pulmonary arterial hypertension (PAH). Recent advances, particularly in PAH management, have highlighted the importance of RV function and stimulated renewed interest in better understanding its adaptation to pressure overload. This is particularly evident over the past year, in which RV function has been reviewed several times $[1,2]$, as has echocardiographic methods of imaging the RV [3], RV function in cardiac and thoracic surgery [4-6], the mechanisms underlying RV failure in $\mathrm{PH}$ [7], and the treatment of acute right heart failure [8].

\section{Chronic RV Pressure Overload}

$\mathrm{PAH}$ is defined as a mean pulmonary artery pressure $>25 \mathrm{~mm} \mathrm{Hg}$ with a pulmonary capillary wedge pressure, left atrial pressure, or left ventricular end-diastolic pressure $\leq 15 \mathrm{~mm} \mathrm{Hg}$ [9]. Historically, long-term outcomes have been quite poor because of progressively increasing hypertension resulting in severe RV failure. But clinical outcomes have significantly improved with the recent advent of several pulmonary-specific vasodilators [10-13], such as prostanoids, endothelin receptor antagonists, and phosphodiesterase 5A (PDE5A) inhibitors. Median survival for patients with PAH without treatment is 2.8 years with 1-, 3 -, and 5-year survival rates of $68 \%, 48 \%$, and $34 \%$, respectively [10]. With continuous prostanoid treatment, survival has improved $87-88 \%, 63-71 \%$, and $56 \%$, respectively $[12,14]$. Similar results have been seen with the oral endothelin receptor antagonist bosentan (82-96\% survival at 1 year; $67-89 \%$ 2-year survival) [15]. RV function is a critical determinant of patient outcomes in PAH and has recently been recognized as an important avenue for further research [16]. RV failure is the end result of $\mathrm{PAH}$ and the cause of at least $70 \%$ of all PAH deaths [10]. Unfortunately, identifying which patients will progress to RV 
failure and at what time in the course of disease has been difficult.

\section{Pathophysiology of RV Adaptation to Chronic Pressure Overload}

One of the key features to RV adaptation to chronic pressure overload is hypertrophy. In general terms, this is felt to be due to increased wall stress due to increased pressure (Laplace's Law). Myocyte size increases via the synthesis of additional sarcomeres [7]. Extracellular matrix increases as well, with resultant increased fibrosis. At some point, adaptation is insufficient in the face of the pressure overload, resulting in dilation, decreased systolic and diastolic function, and frank RV failure. Unfortunately, this sequence of events is not understood well in the RV. There is a decrease in $\alpha$-subtype myosin heavy chain relative to the $\beta$-subtype that is implicated in decreased systolic function $[17,18]$. Actin expression is also altered in $\mathrm{PAH}$, as might be the troponin complex [7]. Pressure overload causes alterations in $\beta$-adrenoreceptor and angiotensin type 1 receptor densities. As with LV failure, RV failure is associated with upregulation of the renin-angiotensin system. RV ischemia also has been documented in PAH indicating that oxygen supply-demand mismatch is likely implicated in the development of RV hypertrophy and failure [19] which may be due to decreased microvasculature recruitment or reduced vasodilatory capacity [7]. Upregulation of myocyte apoptosis in the pressure-overloaded RV also likely contributes to progressive RV dysfunction [7]. Mitochondrial nitric oxide synthase (mtNOS) is upregulated in the hypertrophied RV myocardium and is partially reversed by treatment with the PDE5A inhibitor, sildenafil [20]. These findings are in keeping with prior studies showing increases in PDE5 expression [21], the mitochondrial membrane potential [22], and glucose uptake [23] in RV tissue in patients with PAH and may represent a novel target for RV-specific therapeutic intervention [24].

Regional heterogeneity of RV remodeling and dysfunction has been observed in patients with PAH [25]. Hypertrophy is greatest in the RV outflow tract and worse in patients with decompensated RV function (Figure 1). Regional wall thickening, as a measure of regional function, is significantly decreased in the outflow tract (infundibulum) of patients regardless of RV functional status, with corresponding increased wall stress in this region. Initial reports from our group have suggested that alterations in regional RV structure and function, particularly in the outflow tract, precede overt hemodynamic RV decompensation, in that patients with less severe RV failure have selective outflow tract hypertrophy, whereas patients with severe RV failure have a generalized RV hypertrophy. These results need to be confirmed prospectively in patient cohorts in whom the progression of disease can be followed over time and treatments, but this asymmetrical hypertrophic response is consistent with an earlier study that found greater fiber shortening in the outflow tract compared with the RV sinus region and a sequential timing of contraction in the two regions [26]. Hypertrophy and dysfunction in the outflow tract may be an early sign of RV impending RV failure and suggests that a better understanding of RV remodeling on a regional level may greatly advance our knowledge of RV response to disease.

\section{Identifying RV Dysfunction}

Identifying RV dysfunction at less severe stages, which would allow for earlier intervention and potentially better longterm results, has been limited largely due to complex RV three-dimensional geometry that defies the assumption of a simple ellipsoid, complex LV/septum interactions, and lack of accepted approaches to assess regional and organ-level RV function. Current markers of RV failure that have been associated with poor outcomes only recognize end-stage disease. There have been several recent approaches to better identify RV dysfunction.

The clinically accepted gold standard for identifying RV dysfunction and understanding physiology in the pressureoverloaded state remains invasive hemodynamics [1]. Right atrial pressure, cardiac output, and mean pulmonary arterial pressure all have been prognostic of outcomes in PAH [10]. Measurement of hemodynamics with exercise can further identify PAH not apparent at rest, distinguish from LV diastolic dysfunction, and aid in prognosis (failure to increase cardiac output with exercise) [1]. Pressure-volume loops of RV function in chronic PAH can provide additional information beyond standard hemodynamics. For example, prostacyclin has been shown to improve ventricular-vascular coupling (ratio of contractility as defined by the endsystolic pressure-volume relationship, Ees, to afterload as defined by pulmonary arterial elastance, which itself is the ratio of end-systolic pressure to stroke volume; Figure 2) [27]. This methodology has been used to show enhanced contractility (end-systolic pressure-volume relationship, Ees) despite lower cardiac output and ventricular-vascular decoupling (lower ratio of Ees to pulmonary arterial elastance, Ea) in PAH [28]. Measures of hemodynamics that take into consideration the pulsatility of pulmonary blood flow further offer an opportunity to better understand the hydraulic load that the RV encounters. Increased vasculature stiffness results in increased fluid wave reflections and an increased RV pump workload. While pulmonary vascular resistance (transpulmonary gradient divided by cardiac output) is the clinical standard measurement of pulmonary vascular load, this only provides information on the static load. However, $1 / 3-1 / 2$ of the pulmonary load (hydraulic power) is due to the pulsatile nature of blood flow [1]. Load in a pulsatile flow system is better characterized by input impedance. One recent study of pulmonary vascular input impedance in 49 pediatric patients with PAH predicted clinical outcomes at one year better than pulmonary vascular resistance [29]. Such measures of pulsatile load and ventricular-vascular coupling may help explain when and how the RV fails [30], leading to improved diagnosis and more individualized treatment [31]. 


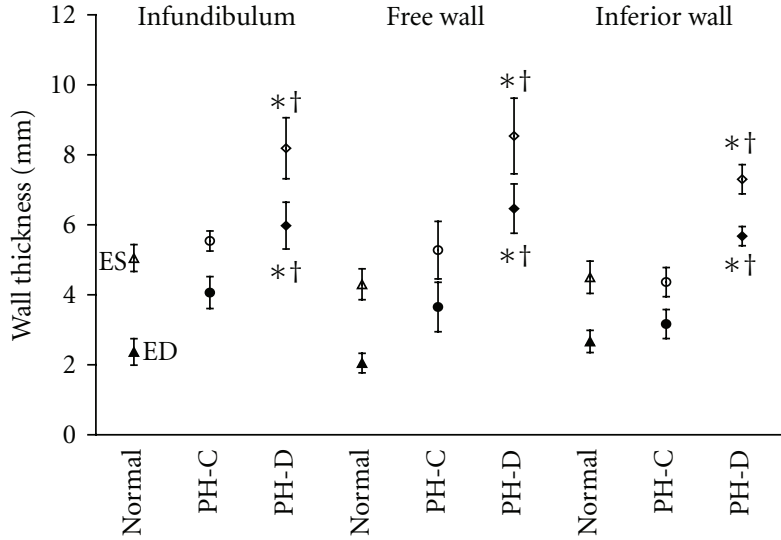

(a)

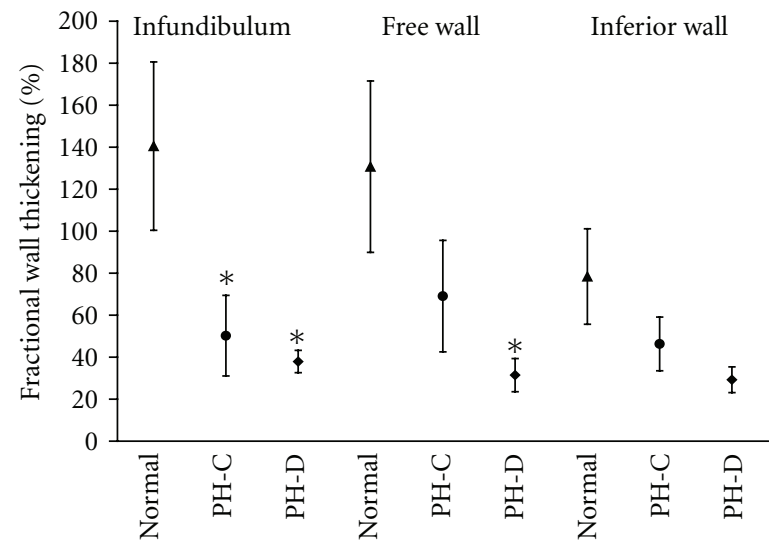

(b)

FIGURE 1: Regional heterogeneity of RV remodeling and dysfunction observed in patients with pulmonary hypertension. Patients were divided into one of three groups based upon hemodynamic parameters: Normal (normal pulmonary artery [PA] pressure, defined as mean PA pressure $\leq 25 \mathrm{mmHg}$ ), $\mathrm{PH}-\mathrm{C}$ ( $\mathrm{PH}$ with hemodynamically compensated RV function, defined as mean PA pressure $>25 \mathrm{mmHg}$ and right atrial [RA] pressure $<10 \mathrm{mmHg}$ ), and $\mathrm{PH}-\mathrm{D}$ ( $\mathrm{PH}$ with hemodynamically decompensated RV function, defined as mean PA pressure $\geq 25 \mathrm{mmHg}$, and RA pressure $\geq 10 \mathrm{mmHg}$ ). (a) Regional RV wall thickness in end diastole (ED, filled symbols) and end systole (ES, open symbols). (b) Corresponding fractional wall thickening. ${ }^{*} P<0.05 \mathrm{PH}-\mathrm{C}$ versus Normal or $\mathrm{PH}-\mathrm{D}$ versus Normal; ${ }^{\dagger} P<0.05 \mathrm{PH}-\mathrm{D}$ versus PH-C, from [25].

Echocardiography is a standard clinical method to assess the RV in PAH. It has, as its major advantage, its noninvasive nature allowing sequential studies over time and good visualization of the major RV structures and functions in a dynamic fashion. Although echocardiographic assessment of pulmonary artery pressure can be made from the tricuspid regurgitant jet, treatment decisions based on PAH hemodynamics need to be confirmed invasively. Additionally, the ability to estimate pulmonary artery pressure from the tricuspid regurgitant jet is quite useful, although for treatment decisions in $\mathrm{PAH}$ hemodynamics must be confirmed invasively. Fractional area change (FAC), as a surrogate of ejection fraction, is calculated by analyzing the difference in the cross-sectional area of the RV in systole and diastole and has prognostic value in small studies, as does RV enlargement, tricuspid regurgitations, pericardial effusion, and the Tei (myocardial performance) index [9]. Newer techniques include tissue Doppler imaging (TDI) and speckle tracking. Peak systolic strain of the RV free wall by TDI is reduced in $\mathrm{PH}$ patients, and this measure correlates with transpulmonary gradient, pulmonary vascular resistance, and cardiac index [32]. RV free wall peak systolic strain has been found to decrease with $\mathrm{PH}$ and decreases further with RV decompensation [33]. TDI of the RV has also demonstrated good correlation with cardiac magnetic resonance (CMR) derived RV ejection fraction [34]. Speckle tracking has also been used to quantify RV myocardial strain and may be a valuable method to detect preclinical disease because it detects minor changes not easily quantified by TDI. For example, speckle tracking RV myocardial strain patterns have identified abnormal RV contraction in systemic sclerosis patients with normal pulmonary pressures, even when other markers such as tricuspid annular plane systolic excursion were unchanged from normal [35-37]. A reliable method to identify pre-clinical RV dysfunction would be an important advance in RV imaging. Three-dimensional echocardiography has been validated as a method to assess RV volumes and has been used to evaluate RV function [38-40]. Limitations of echocardiography include limited acoustic windows for imaging the complex three-dimensional structure of the RV.

CMR has been useful for anatomical assessment of the $\mathrm{RV}$ and more recently functional assessment as well. Two recent reviews of CMR in PAH have recently been published $[41,42]$. RV volume, mass, and stroke index measures by CMR predicted 1-year survival in $64 \mathrm{PAH}$ patients [43]. Measures of PA stiffness by CMR (pulsatility, compliance, capacitance, distensibility, elastic modulus, and the pressureindependent stiffness index) have been reported to be a sensitive measure of early PAH [44]. Blood flow imaging by CMR has been used to detect vortices of blood flow in the main pulmonary artery of patients with PAH [45]. However, many, if not most, measures of RV function by CMR are not yet standardized.

Computed tomography (CT) also can be useful to assess RV structure and function due to its high spatial resolution, accessibility, and quick scan times, though it is limited by radiation and contrast exposure [46-48]. CT has been used to identify regionally heterogeneous $\mathrm{RV}$ remodeling and dysfunction in pulmonary hypertension [25]. This is consistent with findings of a study by CMR and echocardiography that found greater fiber shortening in the outflow tract compared with the RV sinus region [26].

\section{Treatment of Pressure Overload-Induced RV Dysfunction}

Clinical trials data are still quite limited on the effect of PAHspecific treatment on RV function as are data on any specific 


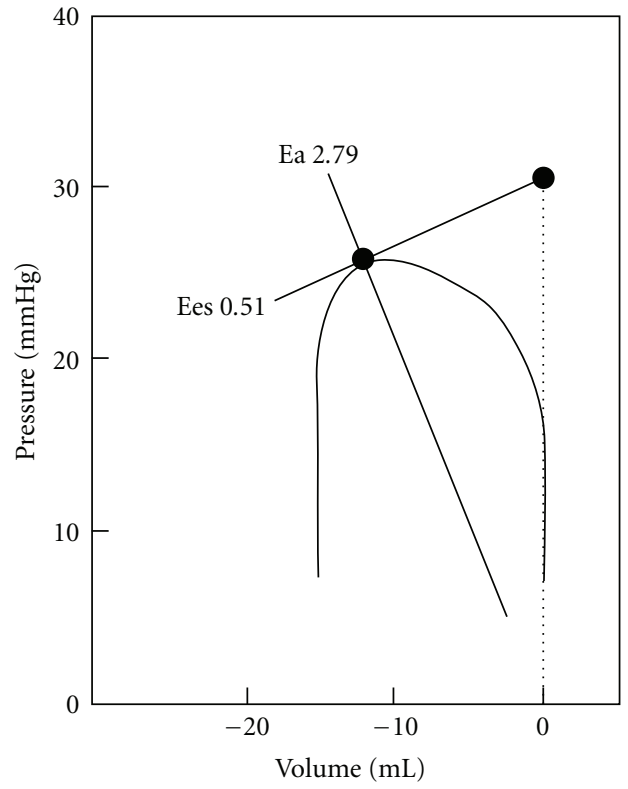

(a)

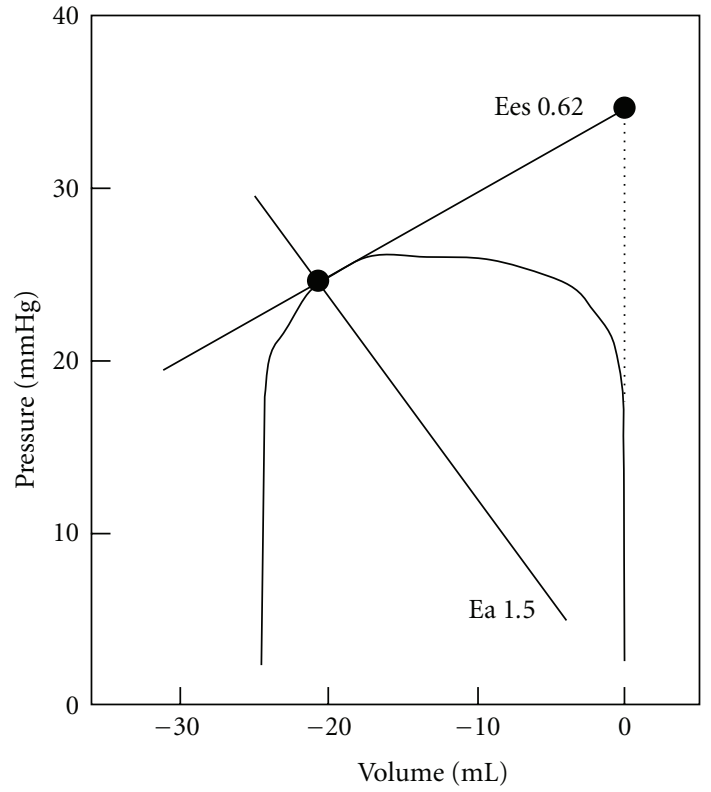

(b)

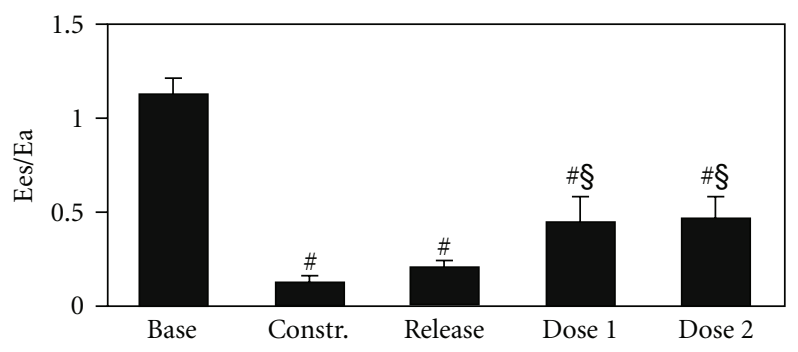

(c)

FIGURE 2: Example of ventricular-vascular coupling analysis. Systolic portions of the RV pressure-volume curves showing end-systolic elastance (Ees) and arterial elastance (Ea) lines. Ventricular-vascular coupling (Ees/Ea) is improved with prostacyclin due to a decrease in arterial elastance (Ea) in a dog with acute RV failure induced by transient pulmonary artery constriction. (a) Prior to prostacyclin infusion. (b) After prostacyclin infusion. (c) Ventricular-vascular coupling efficiency (Ees/Ea) at baseline, during pulmonary artery constriction (Constr.), after pulmonary artery release, and during prostacyclin infusion at 2 doses $\left(n=7\right.$; values are means + standard error). ${ }^{\#} P<0.05$ compared with baseline; ${ }^{\S} P<0.05$ compared with release, adapted from [27].

therapy for RV dysfunction. Regression of RV hypertrophy has been seen after 1 year of treatment with high-dose calcium channel blocker [49]. Prostacyclin treatment has been associated with modest RV reverse remodeling, specifically reversing some dilation and sphericity, as well as improved RV stroke volume $[50,51]$. In a small retrospective study, the endothelin receptor antagonist bosentan resulted in improvements in invasive hemodynamics, functional status, and a trend in improvement in RV stroke volume, but no significant change in RV volume or ejection fraction [52]. The PDE5A inhibitor sildenafil increases RV contractility in isolated rat heart preparations and individual cardiomyocytes [21]. A least one ongoing multicenter PAH treatment study (with bosentan) is currently evaluating RV response to treatment with serial cardiac MRI with results hopefully to be reported within the next year [53].

There are some unique therapies in early-stage investigation that have been reported specifically to improve RV function in the pressure-overloaded state. A plant extract improved RV function in a rat model of PAH with severe RV failure [54]. A tissue-engineered skeletal myoblast sheet improved RV diastolic function, minimized fibrosis, and increased capillary density in a rat model of PAH [55]. There has been a suggested role for RV pacing as cardiac resynchronization therapy in PAH as RV dyssynchronous contraction has been observed to correlate with disease severity [56-58].

\section{Conclusion}

Although our knowledge of RV dysfunction in chronic pressure overload is progressing, there is still much that needs to be understood. Particular attention should be paid to the impact of $\mathrm{PAH}$ on ventricular-vascular interactions and how pathophysiologic derangements result in organ level dysfunction. Regional assessments of the RV may provide an avenue for better understanding mechanisms of RV 
dysfunction and earlier diagnosis because nonhomogeneous RV adaptation appears to be an early marker of impending RV failure in PAH. Importantly, novel therapies to specifically improve RV remodeling and dysfunction in chronic pressure overload are greatly needed.

\section{Disclosures}

Dr. M. A. Simon reports receiving consulting fees or serving on paid advisory boards for Gilead and receiving lecture fees from United Therapeutics and Gilead. Dr. M. R. Pinsky has no conflict of interests.

\section{Acknowlegments}

NHLBI grants KL2 RR024154, HL073198, and HL67181. Its contents are solely the responsibility of the authors and do not necessarily represent the official view of NCRR or NIH. Information on NCRR is available at http://www.ncrr.nih .gov/. Information on Re-engineering the Clinical Research Enterprise can be obtained from http://nihroadmap.nih.gov/ clinicalresearch/overview-translational.asp.

\section{References}

[1] H. C. Champion, E. D. Michelakis, and P. M. Hassoun, "Comprehensive invasive and noninvasive approach to the right ventricle-pulmonary circulation unit state of the art and clinical and research implications," Circulation, vol. 120, no. 11, pp. 992-1007, 2009.

[2] M. A. McDonald and H. J. Ross, "Trying to succeed when the right ventricle fails," Current Opinion in Cardiology, vol. 24, no. 3, pp. 239-245, 2009.

[3] K. D. Horton, R. W. Meece, and J. C. Hill, "Assessment of the right ventricle by echocardiography: a primer for cardiac sonographers," Journal of the American Society of Echocardiography, vol. 22, no. 7, pp. 776-792, 2009.

[4] F. Haddad, P. Couture, C. Tousignant, and A. Y. Denault, "The right ventricle in cardiac surgery, a perioperative perspective-I. Anatomy, physiology, and assessment," Anesthesia and Analgesia, vol. 108, no. 2, pp. 407-421, 2009.

[5] R. W. C. Scherptong, H. W. Vliegen, M. M. Winter et al., "Tricuspid valve surgery in adults with a dysfunctional systemic right ventricle repair or replace?" Circulation, vol. 119, no. 11, pp. 1467-1472, 2009.

[6] A. Pedoto and D. Amar, "Right heart function in thoracic surgery: role of echocardiography," Current Opinion in Anaesthesiology, vol. 22, no. 1, pp. 44-49, 2009.

[7] H. J. Bogaard, K. Abe, A. Vonk-Noordegraaf, and N. F. Voelkel, "The right ventricle under pressure: cellular and molecular mechanisms of right-heart failure in pulmonary hypertension," Chest, vol. 135, pp. 794-804, 2009.

[8] T. Lahm, C. A. McCaslin, T. C. Wozniak et al., "Medical and surgical treatment of acute right ventricular failure," Journal of the American College of Cardiology, vol. 56, no. 18, pp. 1435$1446,2010$.

[9] V. V. McLaughlin, S. L. Archer, D. B. Badesch et al., "ACCF/AHA 2009 expert consensus document on pulmonary hypertension. A report of the American college of cardiology foundation task force on expert consensus documents and the American Heart Association developed in collaboration with the American college of chest physicians; American Thoracic Society, Inc.; and the pulmonary hypertension association," Journal of the American College of Cardiology, vol. 53, no. 17, pp. 1573-1619, 2009.

[10] G. E. D’Alonzo, R. J. Barst, S. M. Ayres et al., "Survival in patients with primary pulmonary hypertension: results from a national prospective registry," Annals of Internal Medicine, vol. 115, no. 5, pp. 343-349, 1991.

[11] V. V. McLaughlin, K. W. Presberg, R. L. Doyle et al., "Prognosis of pulmonary arterial hypertension: ACCP evidence-based clinical practice guidelines," Chest, vol. 126, no. 1, pp. 78S-92S, 2004.

[12] V. V. McLaughlin, A. Shillington, and S. Rich, "Survival in primary pulmonary hypertension: the impact of epoprostenol therapy," Circulation, vol. 106, no. 12, pp. 1477-1482, 2002.

[13] D. B. Badesch, S. H. Abman, G. Simonneau, L. J. Rubin, and V. V. McLaughlin, "Medical therapy for pulmonary arterial hypertension: updated ACCP evidence-based clinical practice guidelines," Chest, vol. 131, no. 6, pp. 1917-1928, 2007.

[14] R. J. Barst, N. Galie, R. Naeije et al., "Long-term outcome in pulmonary arterial hypertension patients treated with subcutaneous treprostinil," European Respiratory Journal, vol. 28, no. 6, pp. 1195-1203, 2006.

[15] V. V. McLaughlin, "Survival in patients with pulmonary arterial hypertension treated with first-line bosentan," European Journal of Clinical Investigation, vol. 36, no. 3, pp. 10-15, 2006.

[16] N. F. Voelkel, R. A. Quaife, L. A. Leinwand et al., "Right ventricular function and failure: Report of a National Heart, Lung, and Blood Institute working group on cellular and molecular mechanisms of right heart failure," Circulation, vol. 114, no. 17, pp. 1883-1891, 2006.

[17] B. D. Lowes, W. Minobe, W. T. Abraham et al., "Changes in gene expression in the intact human heart: downregulation of $\alpha$-myosin heavy chain in hypertrophied, failing ventricular myocardium," Journal of Clinical Investigation, vol. 100, no. 9, pp. 2315-2324, 1997.

[18] T. J. Herron and K. S. McDonald, "Small amounts of $\alpha$ myosin heavy chain isoform expression significantly increase power output of rat cardiac myocyte fragments," Circulation Research, vol. 90, no. 11, pp. 1150-1152, 2002.

[19] A. Gomez, D. Bialostozky, and A. Zajarias, "Right ventricular ischemia in patients with primary pulmonary hypertension," Journal of the American College of Cardiology, vol. 38, no. 4, pp. 1137-1142, 2001.

[20] T. Zaobornyj, L. B. Valdez, D. E. Iglesias, M. Gasco, G. F. Gonzales, and A. Boveris, "Mitochondrial nitric oxide metabolism during rat heart adaptation to high altitude: effect of sildenafil, L-NAME, and L-arginine treatments," American Journal of Physiology, vol. 296, no. 6, pp. H1741-H1747, 2009.

[21] J. Nagendran, S. L. Archer, D. Soliman et al., "Phosphodiesterase type 5 is highly expressed in the hypertrophied human right ventricle, and acute inhibition of phosphodiesterase type 5 improves contractility," Circulation, vol. 116, no. 3, pp. 238248, 2007.

[22] J. Nagendran, V. Gurtu, D. Z. Fu et al., "A dynamic and chamber-specific mitochondrial remodeling in right ventricular hypertrophy can be therapeutically targeted," Journal of Thoracic and Cardiovascular Surgery, vol. 136, no. 1, pp. 168.e3-178.e3, 2008.

[23] M. Oikawa, Y. Kagaya, H. Otani et al., "Increased $[18 \mathrm{~F}]$ fluorodeoxyglucose accumulation in right ventricular free wall in patients with pulmonary hypertension and 
the effect of epoprostenol," Journal of the American College of Cardiology, vol. 45, no. 11, pp. 1849-1855, 2005.

[24] J. Nagendran and E. D. Michelakis, "Mitochondrial NOS is upregulated in the hypoxic heart: implications for the function of the hypertrophied right ventricle," American Journal of Physiology, vol. 296, no. 6, pp. 1723-1726, 2009.

[25] M. A. Simon, C. Deible, M. A. Mathier et al., "Phenotyping the right ventricle in patients with pulmonary hypertension," Clinical and Translational Science, vol. 2, no. 4, pp. 294-299, 2009.

[26] T. Geva, A. J. Powell, E. C. Crawford, T. Chung, and S. D. Colan, "Evaluation of regional differences in right ventricular systolic function by acoustic quantification echocardiography and cine magnetic resonance imaging," Circulation, vol. 98, no. 4, pp. 339-345, 1998.

[27] F. Kerbaul, S. Brimioulle, B. Rondelet, C. Dewachter, I. Hubloue, and R. Naeije, "How prostacyclin improves cardiac output in right heart failure in conjunction with pulmonary hypertension," American Journal of Respiratory and Critical Care Medicine, vol. 175, no. 8, pp. 846-850, 2007.

[28] T. Kuehne, S. Yilmaz, P. Steendijk et al., "Magnetic resonance imaging analysis of right ventricular pressure-volume loops: in vivo validation and clinical application in patients with pulmonary hypertension," Circulation, vol. 110, no. 14, pp. 2010-2016, 2004.

[29] K. S. Hunter, P. F. Lee, C. J. Lanning et al., "Pulmonary vascular input impedance is a combined measure of pulmonary vascular resistance and stiffness and predicts clinical outcomes better than pulmonary vascular resistance alone in pediatric patients with pulmonary hypertension," American Heart Journal, vol. 155, no. 1, pp. 166-174, 2008.

[30] H. A. Ghofrani, R. J. Barst, R. L. Benza et al., "Future perspectives for the treatment of pulmonary arterial hypertension," Journal of the American College of Cardiology, vol. 54, no. 1, pp. S108-S117, 2009.

[31] D. B. Badesch, H. C. Champion, M. A. Gomez Sanchez et al., "Diagnosis and assessment of pulmonary arterial hypertension," Journal of the American College of Cardiology, vol. 54, no. 1, pp. S55-S66, 2009.

[32] N. Rajagopalan, M. A. Simon, M. A. Mathier, and A. Lopez-Candales, "Identifying right ventricular dysfunction with tissue Doppler imaging in pulmonary hypertension," International Journal of Cardiology, vol. 128, no. 3, pp. 359363, 2008.

[33] M. A. Simon, N. Rajagopalan, M. A. Mathier, S. G. Shroff, M. R. Pinsky, and A. Lopez-Candales, "Tissue doppler imaging of right ventricular decompensation in pulmonary hypertension," Congestive Heart Failure, vol. 15, no. 6, pp. 271-276, 2009.

[34] L. E. Sade, Ö. Gülmez, U. Özyer et al., "Tissue doppler study of the right ventricle with a multisegmental approach: comparison with cardiac magnetic resonance imaging," Journal of the American Society of Echocardiography, vol. 22, no. 4, pp. 361$368,2009$.

[35] C. Matias, L. P. D. Isla, M. Vasconcelos et al., "Speckletracking-derived strain and strain-rate analysis: a technique for the evaluation of early alterations in right ventricle systolic function in patients with systemic sclerosis and normal pulmonary artery pressure," Journal of Cardiovascular Medicine, vol. 10, no. 2, pp. 129-134, 2009.

[36] S. R. Jategaonkar, W. Scholtz, T. Butz, N. Bogunovic, L. Faber, and D. Horstkotte, "Two-dimensional strain and strain rate imaging of the right ventricle in adult patients before and after percutaneous closure of atrial septal defects," European Journal of Echocardiography, vol. 10, no. 4, pp. 499-502, 2009.

[37] A. Meris, F. Faletra, C. Conca et al., "Timing and magnitude of regional right ventricular function: a speckle trackingderived strain study of normal subjects and patients with right ventricular dysfunction," Journal of the American Society of Echocardiography, vol. 23, no. 8, pp. 823-831, 2010.

[38] S. T. Schindera, P. S. Mehwald, D. J. Sahn, and D. Kececioglu, "Accuracy of real-time three-dimensional echocardiography for quantifying right ventricular volume: static and pulsatile flow studies in an anatomic in vitro model," Journal of Ultrasound in Medicine, vol. 21, no. 10, pp. 1069-1075, 2002.

[39] M. Hubka, E. L. Bolson, J. A. McDonald, R. W. Martin, B. Munt, and F. H. Sheehan, "Three-dimensional echocardiographic measurement of left and right ventricular mass and volume: in vitro validation," International Journal of Cardiovascular Imaging, vol. 18, no. 2, pp. 111-118, 2002.

[40] T. Menzel, T. Kramm, A. Brückner, S. Mohr-Kahaly, E. Mayer, and J. Meyer, "Quantitative assessment of right ventricular volumes in severe chronic thromboembolic pulmonary hypertension using transthoracic three-dimensional echocardiography: changes due to pulmonary thromboendarterectomy," European Journal of Echocardiography, vol. 3, no. 1, pp. 67-72, 2002.

[41] R. Benza, R. Biederman, S. Murali, and H. Gupta, "Role of cardiac magnetic resonance imaging in the management of patients with pulmonary arterial hypertension," Journal of the American College of Cardiology, vol. 52, no. 21, pp. 1683-1692, 2008.

[42] L. E. R. McLure and A. J. Peacock, "Cardiac magnetic resonance imaging for the assessment of the heart and pulmonary circulation in pulmonary hypertension," European Respiratory Journal, vol. 33, no. 6, pp. 1454-1466, 2009.

[43] S. A. Van Wolferen, J. T. Marcus, A. Boonstra et al., "Prognostic value of right ventricular mass, volume, and function in idiopathic pulmonary arterial hypertension," European Heart Journal, vol. 28, no. 10, pp. 1250-1257, 2007.

[44] J. Sanz, M. Kariisa, S. Dellegrottaglie et al., "Evaluation of pulmonary artery stiffness in pulmonary hypertension with cardiac magnetic resonance," Cardiovascular Imaging, vol. 2, no. 3, pp. 286-295, 2009.

[45] G. Reiter, U. Reiter, G. Kovacs et al., "Magnetic resonancederived 3-dimensional blood flow patterns in the main pulmonary artery as a marker of pulmonary hypertension and a measure of elevated mean pulmonary arterial pressure," Circulation, vol. 1, no. 1, pp. 23-30, 2008.

[46] C. Plumhans, G. Mühlenbruch, A. Rapaee et al., "Assessment of global right ventricular function on 64-MDCT compared with MRI," American Journal of Roentgenology, vol. 190, no. 5, pp. 1358-1361, 2008.

[47] K. Koch, F. Oellig, K. Oberholzer et al., "Assessment of right ventricular function by 16-detector-row CT: comparison with magnetic resonance imaging," European Radiology, vol. 15, no. 2, pp. 312-318, 2005.

[48] S. V. Raman, M. Shah, B. McCarthy, A. Garcia, and A. K. Ferketich, "Multi-detector row cardiac computed tomography accurately quantifies right and left ventricular size and function compared with cardiac magnetic resonance," American Heart Journal, vol. 151, no. 3, pp. 736-744, 2006.

[49] S. Rich and B. H. Brundage, "High-dose calcium channelblocking therapy for primary pulmonary hypertension: evidence for long-term reduction in pulmonary arterial pressure and regression of right ventricular hypertrophy," Circulation, vol. 76, no. 1, pp. 135-141, 1987. 
[50] A. L. Hinderliter, P. W. Willis, R. J. Barst et al., "Effects of longterm infusion of prostacyclin (epoprostenol) on echocardiographic measures of right ventricular structure and function in primary pulmonary hypertension," Circulation, vol. 95, no. 6, pp. 1479-1486, 1997.

[51] R. J. Roeleveld, A. Vonk-Noordegraaf, J. T. Marcus et al., "Effects of epoprostenol on right ventricular hypertrophy and dilatation in pulmonary hypertension," Chest, vol. 125 , no. 2, pp. 572-579, 2004.

[52] K. M. Chin, M. Kingman, J. A. de Lemos et al., "Changes in right ventricular structure and function assessed using cardiac magnetic resonance imaging in bosentan-treated patients with pulmonary arterial hypertension," American Journal of Cardiology, vol. 101, no. 11, pp. 1669-1672, 2008.

[53] 2010, http://clinicaltrials.gov/ct2/show/NCT00433329.

[54] H. J. Bogaard, R. Natarajan, S. C. Henderson et al., "Chronic pulmonary artery pressure elevation is insufficient to explain right heart failure," Circulation, vol. 120, no. 20, pp. 19511960, 2009.

[55] T. Hoashi, G. Matsumiya, S. Miyagawa et al., "Skeletal myoblast sheet transplantation improves the diastolic function of a pressure-overloaded right heart," Journal of Thoracic and Cardiovascular Surgery, vol. 138, no. 2, pp. 460-467, 2009.

[56] A. Lopez-Candales, K. Dohi, N. Rajagopalan et al., "Right ventricular dyssynchrony in patients with pulmonary hypertension is associated with disease severity and functional class," Cardiovascular Ultrasound, vol. 3, article 23, 2005.

[57] J. Lumens, T. Arts, B. Broers et al., "Right ventricular free wall pacing improves cardiac pump function in severe pulmonary arterial hypertension: a computer simulation analysis," American Journal of Physiology, vol. 297, no. 6, pp. H2196-H2205, 2009.

[58] M. L. Handoko, R. R. Lamberts, E. M. Redout et al., "Right ventricular pacing improves right heart function in experimental pulmonary arterial hypertension: a study in the isolated heart," American Journal of Physiology, vol. 297, no. 5, pp. H1752-H1759, 2009. 


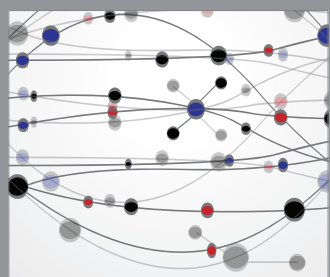

The Scientific World Journal
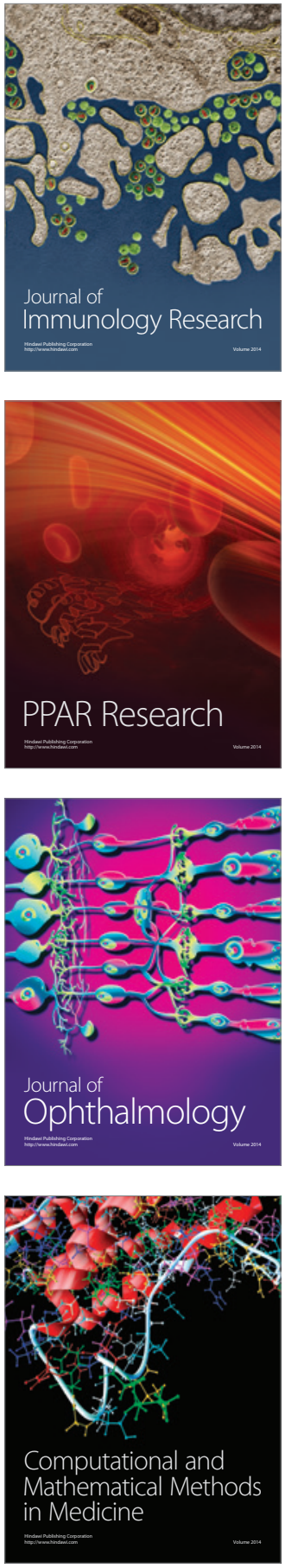

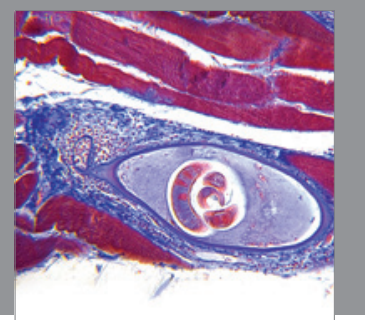

Gastroenterology

Research and Practice
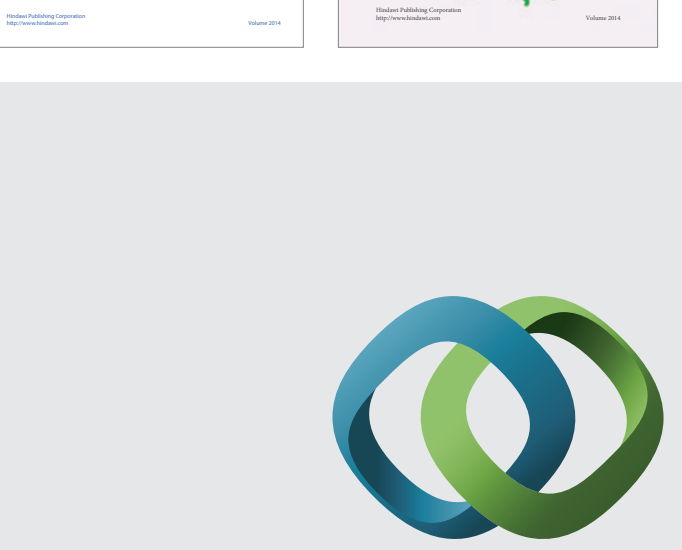

\section{Hindawi}

Submit your manuscripts at

http://www.hindawi.com
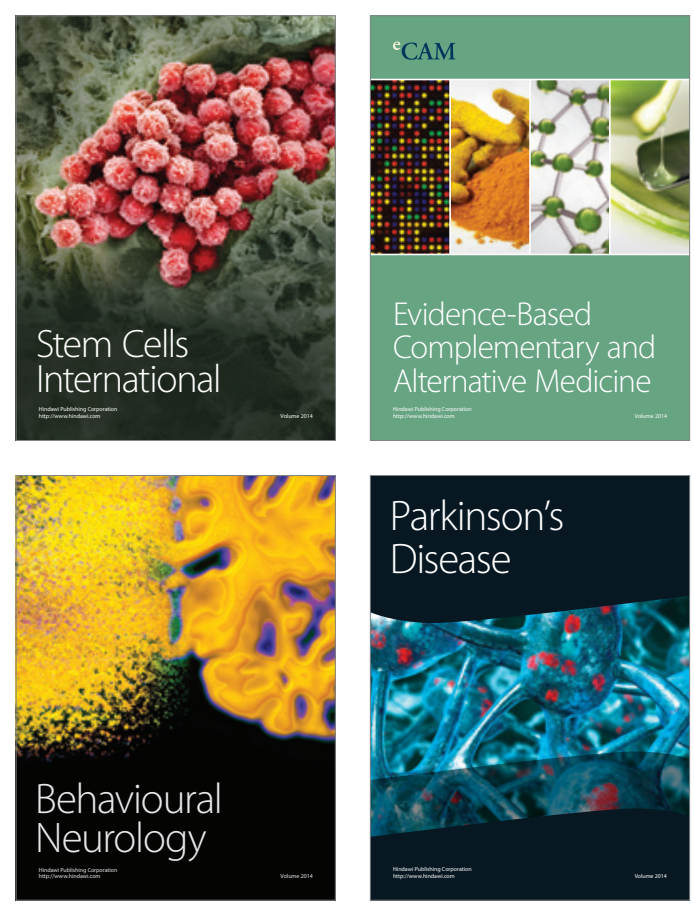

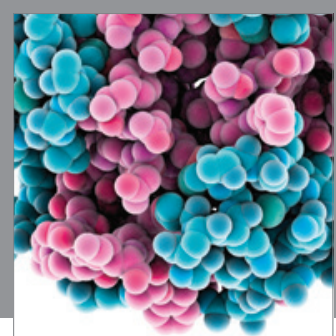

Journal of
Diabetes Research

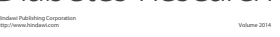

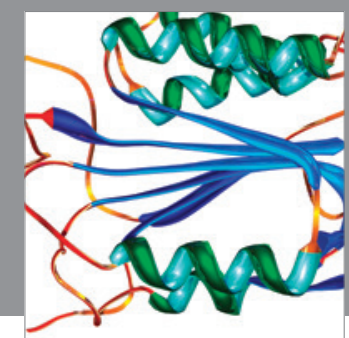

Disease Markers
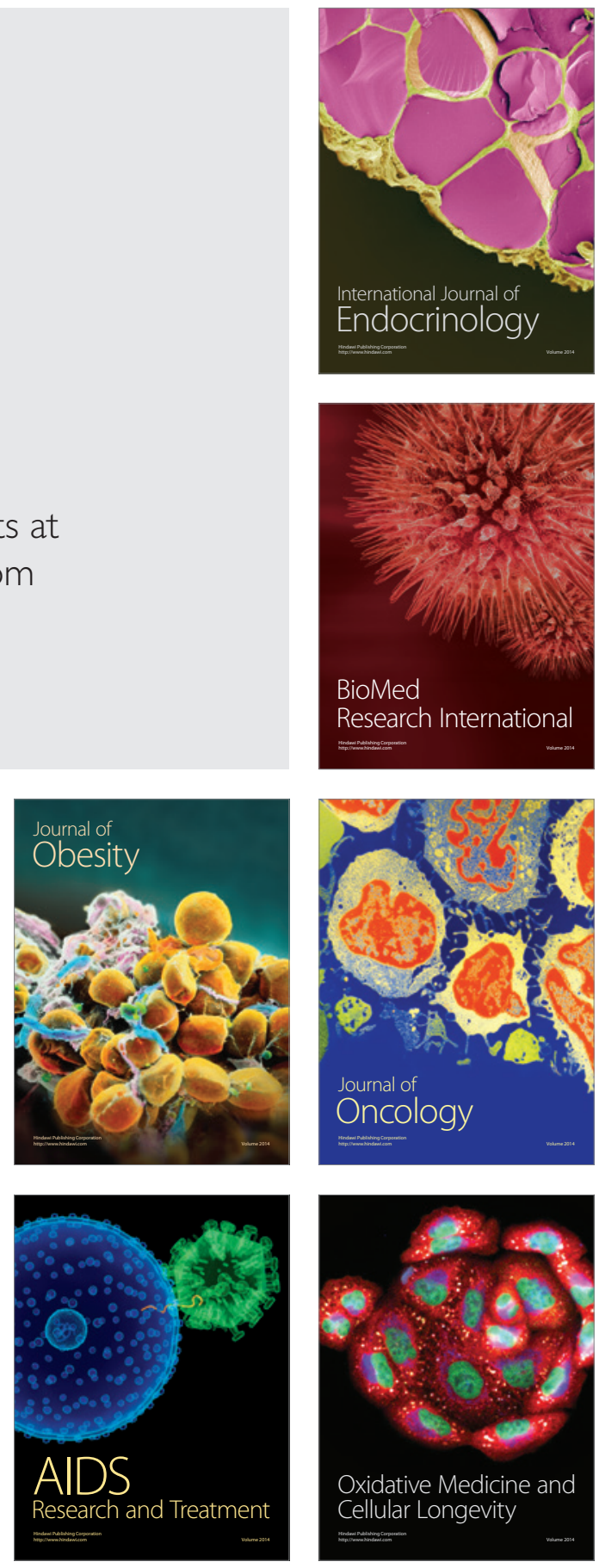